\title{
Context-dependence of Aimed Arm Movements: A Transitory or A Stable Phenomenon?
}

\author{
Benjamin Baak (Corresponding author) \\ Institute of Physiology \& Anatomy, German Sport University Cologne \\ Am Sportpark Müngersdorf 6, 50933 Cologne, Germany \\ E-mail: b.baak@dshs-koeln.de \\ Otmar Bock \\ Institute of Physiology \& Anatomy, German Sport University Cologne \\ Am Sportpark Müngersdorf 6, 50933 Cologne, Germany \\ E-mail: bock@dshs-koeln.de
}

Received: 12-09- 2014

doi:10.7575/aiac.ijkss.v.2n.4p.21
Accepted: 25-10- 2014

URL: http://dx.doi.org/10.7575/aiac.ijkss.v.2n.4p.21
Published: 31-10- 2014

\begin{abstract}
Previous work documented that grasping movements in a typical laboratory context differ widely from those in a more natural context. We evaluate whether this context-dependence changes with experience.

Data from 48 subjects ( 24 female; $24.9 \pm 2.7$ years of age) were (re)analyzed. They had participated in experimental blocks with externally triggered, purposeless and repetitive movements (context L, laboratory-like), and a block with self-initiated, ecologically valid movements embedded in a complex task (context E, everyday-like). Mechanical constraints on grasping were identical in both blocks.

A global metric, representing context-dependence across multiple kinematic parameters, did not change appreciably across the 20 trials of a block. Furthermore, the metric was not affected by prior participation in the other block.

We conclude that context-dependence of grasping is robust, i.e., it shows little influence of prior experience. This opens the avenue for within-subject designs on context-dependence, e.g., for clinical investigations.
\end{abstract}

Keywords: Motor control, Prehension, Context-dependence, Serial order, Attunement

\section{Introduction}

It has repeatedly been argued that tests of motor performance, conducted in a highly constrained laboratory context, may tell us little about motor behavior in real life (Chaytor \& Schmitter-Edgecombe, 2003; Ingram \& Wolpert, 2011). To provide experimental evidence for this view, our group designed a paradigm in which subjects reach to grasp and move a lever in two behavioral contexts (Bock \& Hagemann, 2010). In one, grasping is explicitly instructed, repetitive, externally triggered and serves no ecologically valid purpose, as in typical laboratory research (context L). In the other context, grasping emerges as a natural part of a complex behavioral sequence, is self-generated and serves the purpose of earning a nominal reward, as in many activities of everyday life (context E). Importantly, subjects in both contexts move their hand from the same starting position to the same lever, located in the same place, and move the lever along the same path, i.e., the mechanical task constraints are identical in both contexts. Nevertheless, the registered kinematic and dynamic parameters were found to be widely different, and those differences were traced back to multiple independent processes by factor analysis (Bock \& Züll, 2013).

Further work suggested that the observed context-dependence is not mediated by movement speed, attention focusing or task complexity (Steinberg \& Bock, 2013a), but is related to personality traits: subjects who prefer slow, attentive and prudent processing also showed a larger context-dependence (Steinberg \& Bock, 2013b). Furthermore, contextdependence was more pronounced in old age, and in persons using their non-dominant hand (Bock \& Baak, 2013; Bock \& Steinberg, 2012). We have tentatively attributed our findings to the existence of two occipito-frontal cortical pathways, a dorsal stream involved in quick automated responses and a ventral stream engaged in slow and attentiondemanding behavior (Daprati \& Sirigu, 2006; Goodale \& Milner, 1992; Rossetti \& Pisella, 2002); we postulated a preponderance of the dorsal stream in $\mathrm{E}$ and of the ventral stream in L.

The present work explores the robustness of context-dependence in two respects. While earlier studies dealt with the mean context-dependence within a block of 20 trials, we now address the evolution of context-dependence across trials. It is known that the sensorimotor system gradually attunes to a task by searching, locating and generating task-relevant solutions in the perceptual-motor workspace (Gibson, 1966, 1979), e.g., by means of object manipulation (Davids, Bennett, \& Beak, 2002). We therefore surmised that subjects might gradually attune to a given context, such that response features characteristic for E or L would only emerge later during a block. 
Our second goal was to find out whether subjects' participation in one context affects their performance in another context. Specifically, we postulated that subjects who had been tested in context L, and therefore knew that we were interested in their grasping movements, might not be able to discard this information when they were subsequently tested in context E. In other words, we anticipated that performance in context $\mathrm{E}$ should differ between subjects without prior experience in context L (naive subjects) and those with such experience (non-naive subjects).

No new data were collected for the purpose of this study. Data on the context-dependence of novices have been collected before and the across-block averages have been analyzed and published (Bock \& Baak, 2013; Bock \& Steinberg, 2012). Here we re-analyze those data trial by trial. Data about the context-dependence of persons with prior experience in another context have also been collected but have not been analyzed or published yet. Here we deal with those data for the first time. To our knowledge, this is the first study to evaluate the robustness of contextdependence across trials and across context changes.

\section{Methods}

\subsection{Database}

The experimental procedures for both contexts were described in full detail elsewhere (Bock \& Baak, 2013; Bock \& Steinberg, 2012). In short, the data come from forty-eight young (24 female; $24.9 \pm 2.7$ years of age), right-handed subjects who had no neuromuscular or visual impairments by self-report, except for corrected vision, and had not participated in sensorimotor research before. Data from five subjects had to be deleted due to poor quality. In context L, subjects were instructed by experimenter to grasp a joystick located in front of their body with their right hand, watch for a trigger signal, then move the hand in the horizontal plane towards a lever, grasp the lever with their thumb and index finger, move the lever fore and aft along a rail, and then return the hand to the joystick. In context E, they were instructed to use the joystick for playing a spider-chasing game and earn a nominal reward of $0.02 €$ for each spider caught. At the end of each game level, they had to return the joystick to its central condition, and then move the lever fore and aft to collect their reward and proceed to the next game level. Thus, L and E had the same mechanical constraints, but differed with respect to the behavioral context in which grasping was embedded. The positions of thumb and index fingertip, lever position and lever force were registered at $250 \mathrm{~Hz}$.

Subjects completed a block of 20 grasping movements in one context, and then a block of 20 grasping movements in the other context. The order of contexts was counterbalanced across male as well as across female subjects.

\subsection{Data analysis}

Registered data were reduced by an interactive computer algorithm to 27 parameters per trial, which described the characteristics of hand transport, grip formation, lever prehension and lever motion (see Table 1). For within-block analysis, we then calculated the mean and the coefficient of variation (CV) of each parameter for each hexuple of trials in the first block, not for the whole block, as in our previous studies (Bock \& Baak, 2013; Bock \& Steinberg, 2012). We thus yielded for each subject the mean and $\mathrm{CV}$ of each parameter in trials 1 to 6 , trials 2 to 7 , trials 3 to 8 , and so on through trials 12 to 17 . Trials 18 to 20 were not considered because data were missing in some subjects. Subsequent analyses were limited to those means and CVs which differed significantly between $\mathrm{L}$ and $\mathrm{E}$ either in the first hexuple, in the last hexuple, or in both (t-tests: $\mathrm{p}<0.05$, as marked in Table 1).

Table 1. Parameter descriptions and significant differences between first and last hexuples.

\begin{tabular}{|c|c|c|c|c|}
\hline \multicolumn{2}{|c|}{ Acronym } & Description & \multicolumn{2}{|c|}{$\begin{array}{l}\text { Sig. between first and last } \\
\text { hexuple }\end{array}$} \\
\hline \multirow{7}{*}{ 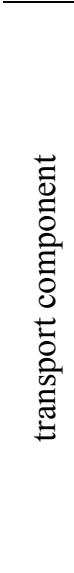 } & TT (s) & $\begin{array}{l}\text { Interval from movement onset to lever contact (transport } \\
\text { time) }\end{array}$ & $\begin{array}{l}\text { Mean } \\
\text { CV }\end{array}$ & $\begin{array}{ll}* \\
\text { n.s. }\end{array}$ \\
\hline & Acc. time & Interval from movement onset to peak velocity & $\begin{array}{l}\text { Mean } \\
\text { CV }\end{array}$ & * \\
\hline & Decc. Time & Interval from peak velocity to lever contact & $\begin{array}{l}\text { Mean } \\
\text { CV }\end{array}$ & $\begin{array}{l}\text { n.s. } \\
\text { n.s. }\end{array}$ \\
\hline & $V_{\max }(\mathrm{cm} / \mathrm{s})$ & Peak tangential hand velocity & $\begin{array}{l}\text { Mean } \\
\mathrm{CV}\end{array}$ & $\begin{array}{l}* \\
* \\
\end{array}$ \\
\hline & Skew-T & Ratio of deceleration time ( $V_{\max }$ to lever contact) and TT & $\begin{array}{l}\text { Mean } \\
\text { CV }\end{array}$ & $\begin{array}{ll}* \\
\text { n.s. }\end{array}$ \\
\hline & Detour-V $(\mathrm{cm})$ & $\begin{array}{l}\text { Maximal vertical detour between actual and shortest possible } \\
\text { hand path }\end{array}$ & $\begin{array}{l}\text { Mean } \\
\text { CV }\end{array}$ & $\begin{array}{l}* \\
\text { n.s. }\end{array}$ \\
\hline & Detour-H (cm) & $\begin{array}{l}\text { Maximal horizontal detour between actual and shortest } \\
\text { possible hand path }\end{array}$ & $\begin{array}{l}\text { Mean } \\
\text { CV }\end{array}$ & $\begin{array}{l}\text { n.s. } \\
*\end{array}$ \\
\hline \multirow{3}{*}{ 苟 } & GT (s) & $\begin{array}{l}\text { Interval from finger opening onset to finger closing } \\
\text { (grasping time) }\end{array}$ & $\begin{array}{l}\text { Mean } \\
\text { CV }\end{array}$ & $\begin{array}{l}* \\
\text { n.s. }\end{array}$ \\
\hline & $\mathrm{PGA}(\mathrm{cm})$ & $\begin{array}{l}\text { Peak 3D distance from thumb to index finger (peak grip } \\
\text { aperture) }\end{array}$ & $\begin{array}{l}\text { Mean } \\
\text { CV }\end{array}$ & $\begin{array}{l}\text { n.s. } \\
*\end{array}$ \\
\hline & Peaks & $\begin{array}{l}\text { (Number of trials with multi-peaked aperture } \\
\text { profiles)/(number of all trials) }\end{array}$ & Mean & n.s. \\
\hline
\end{tabular}




\begin{tabular}{|c|c|c|c|c|}
\hline & $t(\mathrm{PGA})(\mathrm{s})$ & Interval from movement onset to PGA & $\begin{array}{l}\text { Mean } \\
\text { CV }\end{array}$ & n.s. \\
\hline & $t(\mathrm{FGA})(\mathrm{s})$ & Interval from PGA to lever contact & $\begin{array}{l}\text { Mean } \\
\text { CV }\end{array}$ & $\begin{array}{l}\text { n.s. } \\
\text { n.s. }\end{array}$ \\
\hline & Skew-G & Ratio of $t$ (FGA) and GT & $\begin{array}{l}\text { Mean } \\
\text { CV }\end{array}$ & $\begin{array}{lll}* \\
\text { n.s. }\end{array}$ \\
\hline & incli-start $\left(^{\circ}\right)$ & $\begin{array}{l}\text { Hand inclination with respect to the horizontal at movement } \\
\text { onset }\end{array}$ & $\begin{array}{l}\text { Mean } \\
\text { CV }\end{array}$ & $\begin{array}{ll}\text { n.s. } \\
\text { n.s. }\end{array}$ \\
\hline & incli-100 $\left(^{\circ}\right)$ & Hand inclination $100 \mathrm{~ms}$ after onset & $\begin{array}{l}\text { Mean } \\
\text { CV }\end{array}$ & $\begin{array}{lll}* \\
\text { n.s. }\end{array}$ \\
\hline & incli-PGA $\left({ }^{\circ}\right)$ & Hand inclination at time of PGA & $\begin{array}{l}\text { Mean } \\
\text { CV }\end{array}$ & $\begin{array}{l}\text { n.s. } \\
\text { n.s. }\end{array}$ \\
\hline & incli-end $\left(^{\circ}\right)$ & Hand inclination at lever contact & $\begin{array}{l}\text { Mean } \\
\text { CV }\end{array}$ & $\begin{array}{l}\text { n.s. } \\
\text { n.s. }\end{array}$ \\
\hline & Sync-start & $\begin{array}{l}\text { Interval between onsets of finger opening and of } \\
\text { hand transport }\end{array}$ & $\begin{array}{l}\text { Mean } \\
\text { CV }\end{array}$ & $\begin{array}{l}\text { n.s. } \\
\text { n.s. }\end{array}$ \\
\hline ठ․ & Sync-peak & Interval between $t(\mathrm{PGA})$ and $t\left(V_{\max }\right)$ & $\begin{array}{l}\text { Mean } \\
\text { CV }\end{array}$ & $\begin{array}{l}* \\
\text { n.s. }\end{array}$ \\
\hline & RT-lever (s) & $\begin{array}{l}\text { Interval between lever contact and onset of lever motion } \\
\text { (reaction time) }\end{array}$ & $\begin{array}{l}\text { Mean } \\
\text { CV }\end{array}$ & $\begin{array}{l}\text { n.s. } \\
\text { n.s. }\end{array}$ \\
\hline$\vec{\Xi}$ & $\mathrm{F}-100(\mathrm{~N})$ & Force compressing the lever $100 \mathrm{~ms}$ after lever contact & $\begin{array}{l}\text { Mean } \\
\text { CV }\end{array}$ & $\begin{array}{lll} \\
\text { n.s. }\end{array}$ \\
\hline ڤ્ڤ & $\begin{array}{l}\text { TQ-100 } \\
(\mathrm{N} / \mathrm{mm})\end{array}$ & 3D lever torque $100 \mathrm{~ms}$ after lever contact & $\begin{array}{l}\text { Mean } \\
\text { CV }\end{array}$ & $\begin{array}{l}\text { n.s. } \\
\text { n.s. }\end{array}$ \\
\hline $\begin{array}{l}0 \\
0 \\
0 \\
0\end{array}$ & Fmax $(\mathrm{N})$ & Maximal force compressing the lever & $\begin{array}{l}\text { Mean } \\
\text { CV }\end{array}$ & $\begin{array}{l}* \\
\text { n.s. }\end{array}$ \\
\hline$\frac{0}{\stackrel{0}{\underline{E}}}$ & $\begin{array}{l}\text { TQmax } \\
(\mathrm{N} / \mathrm{mm})\end{array}$ & Maximal 3D lever torque & $\begin{array}{l}\text { Mean } \\
\text { CV }\end{array}$ & $\begin{array}{l}* \\
\text { n.s. }\end{array}$ \\
\hline 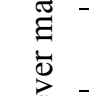 & $\mathrm{t}(\mathrm{Fmax})(\mathrm{s})$ & Interval between lever contact and Fmax & $\begin{array}{l}\text { Mean } \\
\text { CV }\end{array}$ & $\begin{array}{l}\text { n.s. } \\
\text { n.s. }\end{array}$ \\
\hline 己 & $\mathrm{t}(\mathrm{TQmax})(\mathrm{s})$ & Interval between lever contact and TQmax & $\begin{array}{l}\text { Mean } \\
\text { CV }\end{array}$ & $\begin{array}{l}\text { n.s. } \\
\text { n.s. }\end{array}$ \\
\hline & $\mathrm{LT}(\mathrm{s})$ & Interval between onset and end of lever motion (lever time) & $\begin{array}{l}\text { Mean } \\
\text { CV }\end{array}$ & $\begin{array}{l}\text { n.s. } \\
\text { n.s. }\end{array}$ \\
\hline
\end{tabular}

The first column represents parameter descriptions, as defined in the second column for each parameter. The third column lists significant differences between first and last hexuples of the naive block for parameter means and corresponding CVs. Note that based on the calculation of parameter Peaks, no CV was available. The symbols * denote the significance levels $\mathrm{p}<.05$, while n.s. denotes the lack of significnace.

In order to calculate a global metric across all selected means and CVs, we normalized the scores with respect to the last hexuple, using

$$
\Delta_{s}=\frac{p_{s}(\mathrm{i})-\mathrm{E}(12)}{L(12)-E(12)}
$$

where $p_{S}(i)$ is a parameter score (mean or CV) of subject $S$ in the $i$ 'th hexuple, while $E(12)$ and $L(12)$ are the acrosssubject means in the last hexuple of contexts $E$ and $L$, respectively. Thus, $D_{s}=1$ denotes that an individual score $p_{S}(i)$ equals $\mathrm{L}(12)$, and $\mathrm{D}_{\mathrm{s}}=0$ denotes that $\mathrm{p}_{\mathrm{S}}(\mathrm{i})$ equals $\mathrm{E}(12)$. If subjects indeed attune to the two contexts (see Introduction), the globalized metric should gradually increase toward 1.00 for subjects tested in context L and gradually decrease toward 0.00 for subjects tested in context E. Conversely, if the context-dependence is robust against serial-order effects, the globalized metric should be consistently near 1.00 for subjects tested in L and consistently near 0.00 for subjects tested in E. Equation (1) is adapted from an earlier study (Steinberg \& Bock, 2013a) and includes a sliding-average calculation.

The normalized scores were then averaged across parameters and, as the last step of within-block calculations, the outcome was submitted to an analysis of variance (ANOVA) with the between-factor Context (L, E) and the within factor hexuple $(1,2,3, \ldots 12)$.

For between-block analyses, we calculated the means and CVs of the same parameters across all trials of the first block, and separately across all trials of the second block. The outcome was then normalized in analogy to Eq. (1), using

$$
\Delta_{S}=\frac{p_{S}(\text { block 1 })-E(\text { block 2 })}{L(\text { block 2) }-E(\text { block 2) }}
$$


The scores thus yielded were averaged across parameters, and the outcome was submitted to an ANOVA with the between-factors Context (L, E) and Block $(1,2)$.

\section{Results}

Figure 1 represents the normalized scores of an exemplary parameter, acceleration time, for the first and last hexuples of the first block in a subject who participated in context $\mathrm{L}$ and a subject who participated in context E. These two subjects exhibit an above-average context dependence of acceleration time, since the normalized scores in L are above 1.00 and those in E are below 0.00 . This context-dependence even increases slightly from the first to the last hexuple, as the curves diverge.

The globalized metric of Eq. (1) allows us to determine whether the trend observed in Fig. 1 is consistent not only across subjects but also across parameters.
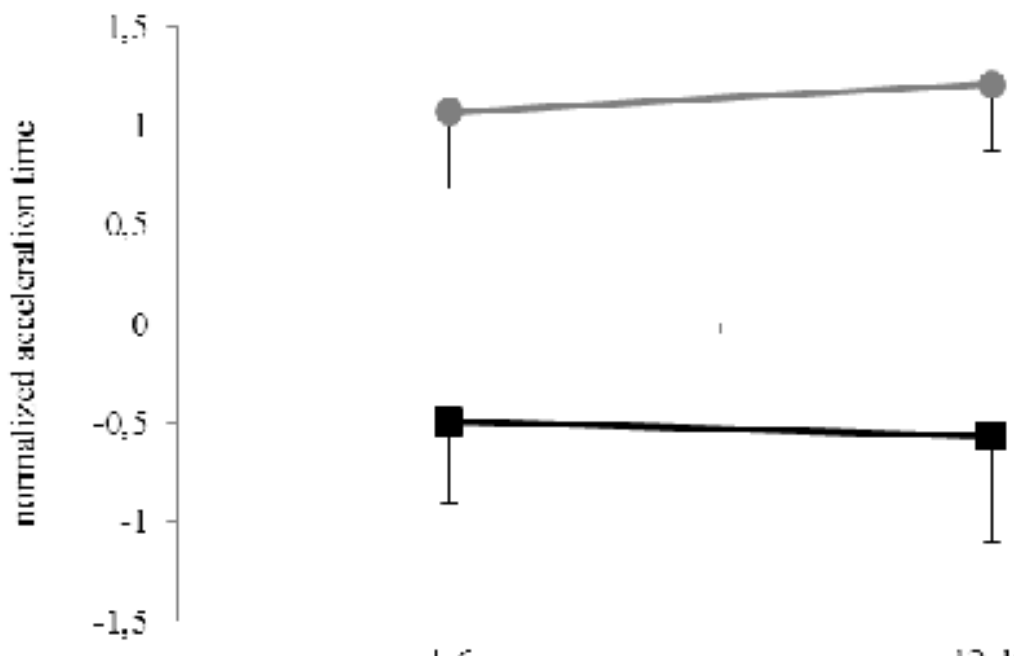

$1-6$

$12-17$

trial number

Figure 1.Exemplary parameter: normalized acceleration time.

Data are from the first block of subject KL, tested in context L, and from subject CG, tested in context E. Symbols represent means and error bars and the pertinent standard deviations from the first hexuple (trial 1-6) and the last hexuple (trial 12-17). Since the data are normalized, the ordinate is dimensionless.

Figure 2 illustrates that this was not the case. The graphs for $\mathrm{L}$ and $\mathrm{E}$ seem to run more or less in parallel across all hexuples. Accordingly, ANOVA yielded a significant effect for Context $(\mathrm{F}(1,41)=61.11 ; \mathrm{p}<.001)$ and Order $(\mathrm{F}(11$, $451)=2.12 ; \mathrm{p}<.05)$, but not for their interaction $(\mathrm{F}(11,451)=.96 ; \mathrm{p}>.05)$.

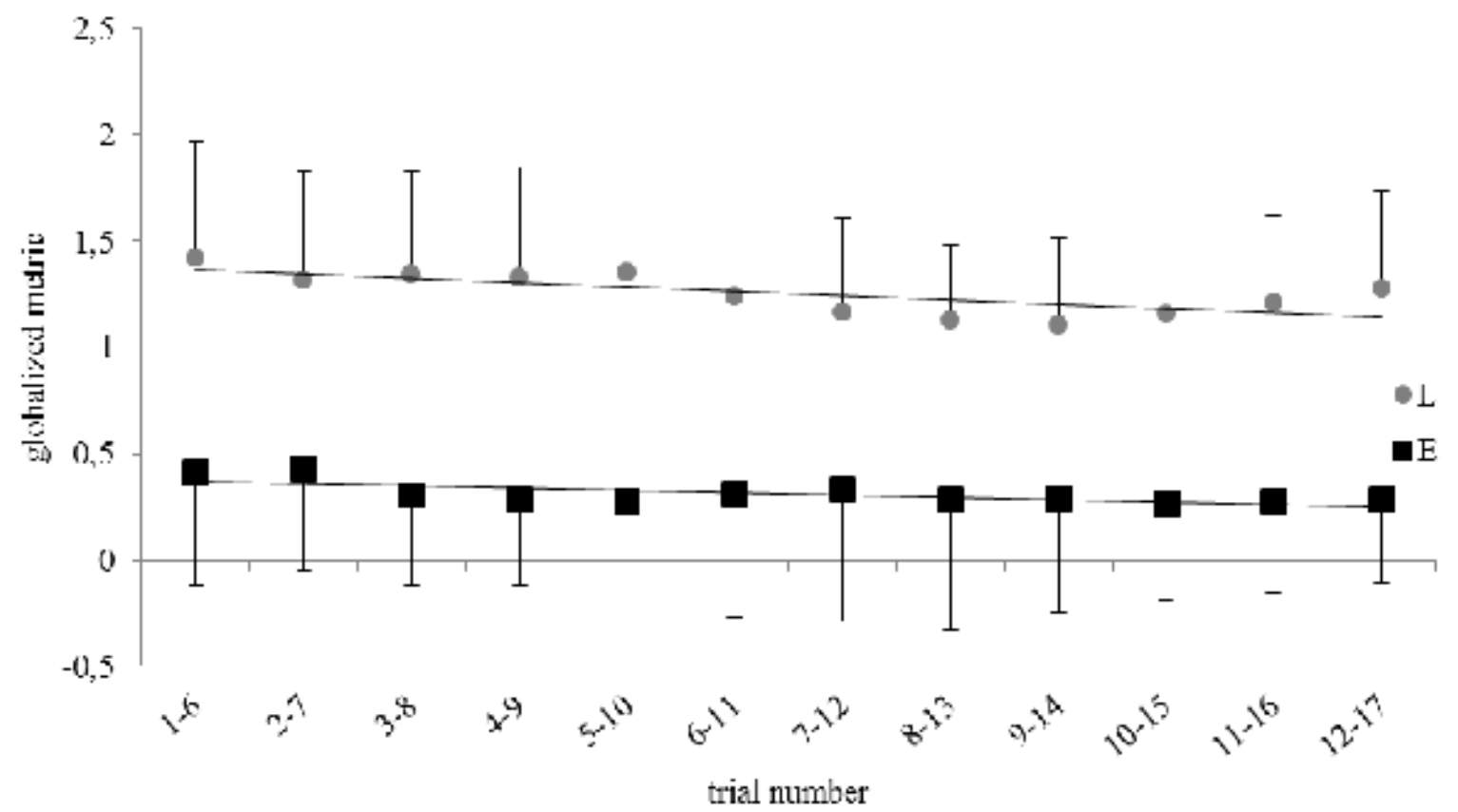

Figure 2. Sequence effects within the first block 
Globalized metric for each hexuple in the first block of subjects tested in L versus in E. Error bars represent betweensubject standard deviations. Since the data are normalized, the ordinate is dimensionless.

Figure 3 is analogous to Figure 2 except that the two blocks are compared, rather than the hexuples from the first block. Again, the graphs for L and E seem to run more or less in parallel. ANOVA yielded a significant effect only for Context $(F(1,82)=108.65 ; p<.001)$, but not for Order $(F(1,82)=.01 ; p>0.05)$ or the interaction $(F(1,82)=3.33 ; p>.05)$.
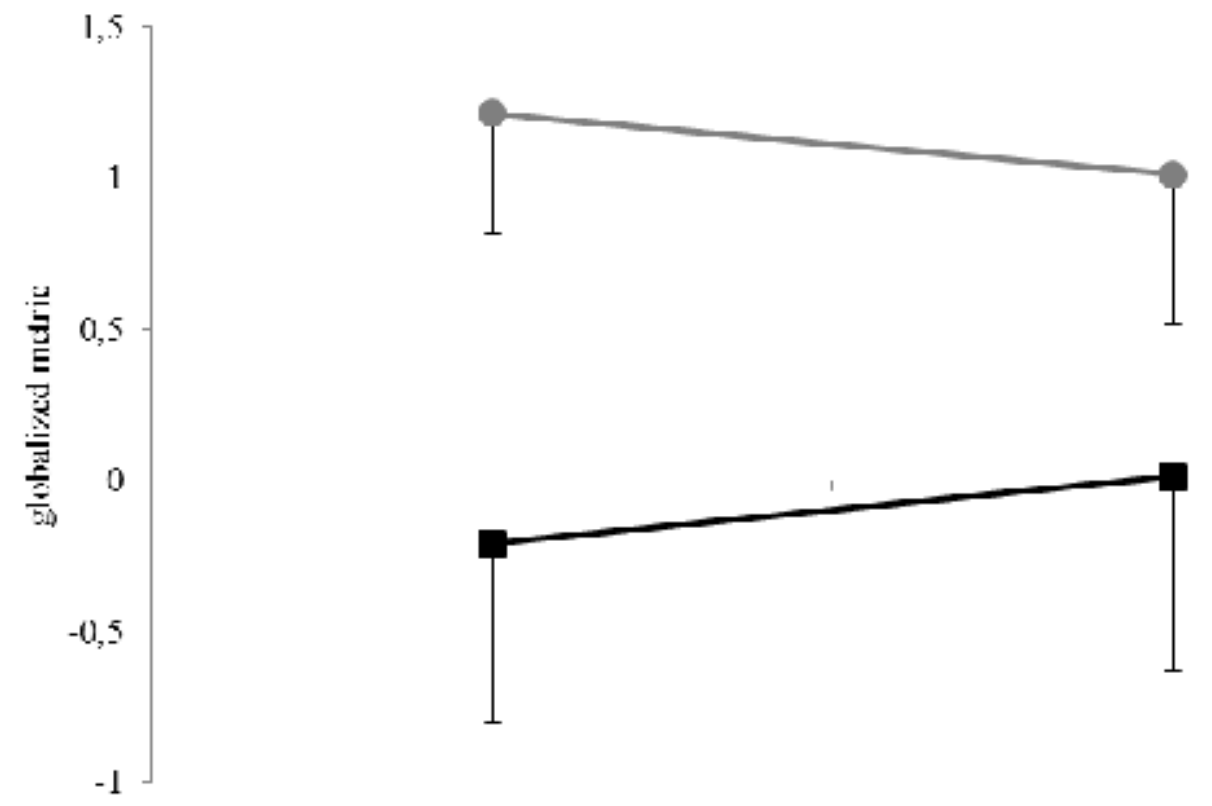

naive

nun-nuive

block

Figure 3. Order effects between the first and the second block

Global parameter values for the first and the second block in L versus in E. Only parameters with significant effect of Task are presented. Error bars represent between-subject standard deviations. Since the data are normalized, the ordinate is dimensionless.

\section{Discussion}

This study evaluated whether the previously observed context-dependence of grasping is consistent across trials and across blocks of trials with different contexts. A within-block analysis revealed that the difference between $\mathrm{L}$ and $\mathrm{E}$ remains quite constant: parameters do change from the beginning to the end of the first block (i.e., significant effect of Order), but they change more or less in parallel for both contexts (i.e., no significance of Context x Order). We thus found no support for the view (see Introduction) that grasping kinematics and dynamics gradually attune to a given context; rather, they seem to reflect that context from the first trial onward. Our interpretation for this outcome is that subjects were aware of the context well before the first trial started, since they were asked beforehand to participate in research on grasping (for L) or to play a computer game (for E). Based on this advance knowledge, they could attune their sensorimotor system to the respective context ahead of time, and stay attuned throughout the experimental block.

A between-block analysis yielded that the difference between $\mathrm{L}$ and $\mathrm{E}$ is similar in both blocks, i.e., the contextdependence of novices is comparable to that of subjects who had previously participated in the other context. We thus have found no evidence that information related to a given context might persist in short-term motor memory and interfere with information related to a subsequent context. Specifically, we found no evidence that subjects who participated first in L, and thus were aware that their grasping was being analyzed, transferred this knowledge to the subsequent testing in E and grasped there as if they were still in L. Rather, subjects apparently could switch quickly from one context to the other.

Summing up, the present analyses confirm that the context-dependence of grasping is a robust phenomenon. Previous work has documented that it persists across multiple studies, gravity levels, hands and age groups (Bock \& Baak, 2013; Bock \& Steinberg, 2012, Steinberg \& Bock, 2013a) while the present work shows that it is stable across trials in the same context and is not modified by preceding trials in another context. This opens up an avenue for clinical research where context-dependence is best assessed in a within-subject design (see Introduction). For example, the contextdependence of motor deficits in patients following stroke should be assessed by within-patient comparisons, since comparisons between patients are hampered by interindividual differences in the time since stroke, in lesion size and site, and in treatment regimen. 


\section{Acknowledgements}

We thank Thomas Kesnerus for software development and the team of Hans-Martin Küsel-Feldker for hardware modifications. We also wish to thank Fabian Steinberg for his support in designing the experiment and procedures. This study was supported by the Center for Human Integrative Physiology in Space of the German Sport University Cologne.

\section{References}

Bock, O., \& Baak, B. (2013). Dependence of manual grasping on the behavioral context: A comparison between arms and between age groups. Psychology, 4(12), 998-1003. doi:10.4236/psych.2013.412144

Bock, O., \& Hagemann, A. (2010).An experimental paradigm to compare motor performance under laboratory and under everyday-like conditions. Journal of Neuroscience Methods, 193(1), 24-28. doi:10.1016/j.jneumeth.2010.08.005

Bock, O., \& Steinberg, F. (2012).Age-related deficits of manual grasping in a laboratory versus in an everyday-like setting. Ageing Research, 3(1). doi:10.4081/ar.2012.e7

Bock, O., \& Züll, A. (2013).Characteristics of grasping movements in a laboratory and in an everyday-like context. Human Movement Science, 32(1), 249-256. doi:10.1016/j.humov.2012.12.009

Chaytor, N., \& Schmitter-Edgecombe, M. (2003). The ecological validity of neuropsychological tests: A review of the literature on everyday cognitive skills. Neuropsychology Review, 13(4), 181-197.

doi:10.1023/B:NERV.0000009483.91468.fb

Daprati, E., \& Sirigu, A. (2006). How we interact with objects: Learning from brain lesions. Trends in Cognitive Sciences, 10(6), 265-270. doi:10.1016/j.tics.2006.04.005

Davids, K., Bennett, S. J., \& Beak, S. (2002). Sensitivity of children and adults to haptic information in wielding tennis racquets. In K. Davids, G. Savelsbergh, S. J. Bennett, \& J. van der Kamp (Eds.), Interceptive actions in sport: Information and Movement (pp. 195-211). London: Routledge.

Gibson, J. J. (1966). The senses considered as perceptual systems. London: George Allen \& Unwin.

Gibson, J. J. (1979). The ecological approach to visual perception. Boston: Houghton Mifflin.

Goodale, M., \& Milner, A. (1992). Separate visual pathways for perception and action. Trends in Neurosciences, 15(1), 20-25. doi:10.1016/0166-2236(92)90344-8

Ingram, J. N., \&Wolpert, D. M. (2011). Naturalistic approaches to sensorimotor control. Progress in Brain Research, 191, 3-29. doi:10.1016/B978-0-444-53752-2.00016-3

Rossetti, Y., \& Pisella, L. (2002). Several "Vision for Action" systems: a guide to dissociating and integrating dorsal and ventral functions (tutorial). In W. Prinz \& B. Hommel (Eds.), Attention and performance; common mechanisms in perception and action (pp. 62-119). Oxford: Oxford University Press.

Steinberg, F., \& Bock, O. (2013a). Context dependence of manual grasping movements in near weightlessness. Aviation, Space, and Environmental Medicine, 84(5), 467-472. doi:10.3357/ASEM.3348.2013

Steinberg, F., \& Bock, O. (2013b). Influence of cognitive functions and behavioral context on grasping kinematics. Experimental Brain Research, 225(3), 387-397. doi:10.1007/s00221-012-3379-y 